\title{
Sustainability via Active Garden Education (SAGE): results from two feasibility pilot studies
}

Rebecca E. Lee ${ }^{1 *}$, Nathan H. Parker ${ }^{2}$, Erica G. Soltero ${ }^{1}$, Tracey A. Ledoux², Scherezade K. Mama ${ }^{3}$ and Lorna McNeill ${ }^{4}$

\begin{abstract}
Background: Low physical activity (PA) and fruit and vegetable ( $F \& V$ consumption in early childhood are continued public health challenges. This manuscript describes outcomes from two pilot studies for Sustainability via Active Garden Education (SAGE), a program designed to increase PA and F\&V consumption among 3 to 5 year old children.

Methods: SAGE was developed using community-based participatory research (CBPR) and delivered to children ( $N=$ 89) in early care and education centers (ECEC, $N=6$ ) in two US cities. Children participated in 12 one-hour sessions that included songs, games, and interactive learning activities involving garden maintenance and taste tests. We evaluated reach, efficacy, adoption, implementation, and potential for maintenance of SAGE following the RE-AIM framework. Reach was evaluated by comparing demographic characteristics among SAGE participants and residents of target geographic areas. Efficacy was evaluated with accelerometer-measured PA, F\&V consumption, and eating in the absence of hunger among children, parenting practices regarding PA, and home availability of F\&V. Adoption was evaluated by the number of ECEC that participated relative to the number of ECEC that were recruited. Implementation was evaluated by completion rates of planned SAGE lessons and activities, and potential for maintenance was evaluated with a parent satisfaction survey.
\end{abstract}

Results: SAGE reached ECEC in neighborhoods representing a wide range of socioeconomic status, with participants' sociodemographic characteristics representing those of the intervention areas. Children significantly increased PA during SAGE lessons compared to usual lessons, but they also consumed more calories in the absence of hunger in post- vs. pre-intervention tests (both $p<.05$ ). Parent reports did not suggest changes in F\&V consumption, parenting PA practices, or home F\&V availability, possibly due to low parent engagement. ECEC had moderate-to-high implementation of SAGE lessons and curriculum. Potential for maintenance was strong, with parents rating SAGE favorably and reporting increases in knowledge about PA and nutrition guidelines for young children.

Conclusions: SAGE successfully translated national PA guidelines to practice for young children but was less successful with nutrition guidelines. High adoption and implementation and favorable parent reports suggest high potential for program sustainability. Further work to engage parents and families of young children in ECEC-based PA and nutrition programming is needed.

Keywords: Children, Preschool, Physical activity, Fruit, Vegetables, Eating behavior, Early intervention, Curriculum, Program evaluation

\footnotetext{
* Correspondence: releephd@yahoo.com

${ }^{1}$ Center for Health Promotion and Disease Prevention, College of Nursing

and Health Innovation, Arizona State University, Phoenix, AZ, USA

Full list of author information is available at the end of the article
}

(c) The Author(s). 2017 Open Access This article is distributed under the terms of the Creative Commons Attribution 4.0 International License (http://creativecommons.org/licenses/by/4.0/), which permits unrestricted use, distribution, and reproduction in any medium, provided you give appropriate credit to the original author(s) and the source, provide a link to the Creative Commons license, and indicate if changes were made. The Creative Commons Public Domain Dedication waiver (http://creativecommons.org/publicdomain/zero/1.0/) applies to the data made available in this article, unless otherwise stated. 


\section{Background}

Low physical activity (PA) and fruit and vegetable (F\&V) consumption in early childhood contribute to obesity and related health compromising conditions later in the life course [1-10]. Healthy behaviors such as physical activity (PA) [9] and dietary habits [1-4], develop in early childhood and track through youth, with weight status tracking into adulthood [1, 5-8, 10]. There are inverse associations between PA and childhood obesity across all age groups [11-14], and exposure to a healthy diet early in life can promote a lifetime of healthy dietary habits $[1,4,8]$. The 2011 US Institute of Medicine's (IOM) Early Childhood Obesity Prevention Policies Report identified early care and education centers (ECEC) as a primary target for behavioral intervention, because most young children in the US ( $<5$ years) are enrolled in an ECEC [15]. Among preschool aged children, the ECEC is the setting where children are the most sedentary throughout their entire day [16]. Innovative strategies are needed to increase PA and reduce sedentary time as well as to promote healthy eating habits in ECEC [17].

Garden-based education has increased in popularity with schools, families and children [18-22]. Previous work has suggested community input is important for development, implementation and sustainability of garden-based interventions for school-age children [23]. Involving stakeholders via a participatory approach can help increase the reach of intervention efforts and enhance execution of intervention protocols by promoting feasible strategies. This, in turn, can produce more robust outcomes and increase efficacy and promote long term adoption essential for broad based dissemination [22]. Similarly, results from development efforts for the intervention pilot study described herein suggest that involving ECEC staff, parents, and community members in these processes improves potential for success [24]. There has been little focus on PA in garden-based interventions among young children [22], with most existing interventions aiming to improve dietary habits with mixed success [22, 25-31]; although, one study in school aged children (grades 4 and 5, usually about age 9 and 10 years) reported that garden curricula can increase active time in school [32]. The few studies that have tested the effect of garden interventions on PA and F\&V consumption neglected to evaluate factors that may impact internal and external validity (i.e., reach, efficacy, adoption, implementation, maintenance) [22]. These factors are vital to informing potential future implementation, adoption and sustainability of evidence-based interventions [33, 34].

Unlike previous interventions in ECEC [35-39], the Sustainability via Active Garden Education (SAGE) curriculum used a community-based participatory research
(CBPR) approach to meet US national guidelines [15] and US ECEC accreditation standards [40]. CBPR approaches are inherently ecologic, incorporating voices from community members, practitioners, and policy makers. Thus, this study was guided by the Ecologic Model of Physical Activity (EMPA) [41, 42], which posits that micro-level environmental settings like the ECEC can create opportunities for PA and for F\&V consumption that can directly determine day-to-day choices. The EMPA further suggests dynamic linkages such that health promotion efforts in ECEC may produce secondary impacts transferring to the home environment (and vice versa) via exo-environmental linkages (e.g., greater parent awareness, home availability of $F \& V$ owing to child requests based on experiences in ECEC) [43, 44]. These exo-environmental linkages eventually influence macro-level policies at the center and community level that can reduce health disparities [43, 44].

This study tested the efficacy of the SAGE intervention in two pilot projects and evaluated the internal and external validity of the pilot tests using the RE-AIM framework. SAGE was developed using a CBPR strategy over 6 years [24] and was piloted as a 12-session, gardenbased, feasibility trial implemented in ECEC to increase PA and F\&V consumption [45]. Following a RE-AIM strategy [33, 34], we developed and tested the reach, efficacy, adoption, implementation and potential for maintenance of SAGE in two pilot studies in two cities. Investigation of efficacy-related outcomes was hypothesis-driven, whereas investigation of reach, adoption, implementation and potential for maintenance outcomes was exploratory. Reach was defined as the representativeness of our sample of participating children. We evaluated the efficacy of SAGE on improving PA, F\&V intake, and hunger and fullness cues among children, as well as PA parenting practices and the home availability of $F \& V$. It was hypothesized that SAGE would increase PA, F\&V intake, and response to hunger and fullness cues among children in ECEC and improve PA parenting practices and home availability of F\&V outside of ECEC. Adoption was measured by the number of eligible sites that participated, and implementation of sessions delivered. The potential for maintenance was evaluated with parent surveys.

\section{Methods}

\section{Participants and intervention design}

SAGE was implemented in the US by trained research staff in four ECEC in Houston, Texas (SAGE 1) and in two ECEC in Phoenix, Arizona (SAGE 2). All centers were licensed and accredited offering full and half day care to preschool aged children. All students between the ages of 3-5 who were enrolled in the preschool class at each participating center were eligible to participate. 
A sub-sample of parents $(N=20)$ from SAGE 2 completed a demographic survey, parenting PA practices questionnaire, and a satisfaction survey following the intervention; specific sample sizes by instrument are presented in Table 1. Unique among previous, nutritionbased curricula, SAGE was designed to source concepts from the plant life cycle as metaphors for humans growing into healthy and strong adults. This creative approach to garden-based ECEC curricula emanated from community partners and purposed to increase interest and engagement among teachers and learners. SAGE promoted, and offered opportunities for, increasing PA, reducing sedentary time, and improving knowledge of, appreciation for, and consumption of F\&V. Feedback from implementers, our $\mathrm{CAB}$ and ECEC directors in SAGE 1 helped to fine-tune SAGE 2; thus, results are presented separately for each of the pilot studies. Detailed description of the development of the SAGE intervention protocol has been presented previously [46].

\section{Recruitment of ECEC}

SAGE Pilots 1 and 2 were conducted using identical recruitment methods. ECEC within a five-mile radius of the University campus were identified. In both cases, the neighborhoods surrounding the campuses were lower to middle SES and had higher proportions of ethnic minorities residing there. In collaboration with our Partnership and $\mathrm{CAB}$, a colorful and inviting postcard was developed and sent to ECEC directors. Using a standardized script, research assistants followed up with directors within 1 week with a phone call and email to describe the project. Four out of five centers contacted in Houston SAGE Pilot 1 enrolled. The director of the fifth center decided not to participate, owing to scheduling conflicts, such as

Table 1 Individual measurement instruments and participants' participation

\begin{tabular}{|c|c|c|c|c|c|}
\hline Instrument & $\begin{array}{l}\text { Participant who } \\
\text { was measured }\end{array}$ & $\begin{array}{l}\text { Pilot } \\
\text { Study }\end{array}$ & $\mathrm{T} 1$ & $\begin{array}{l}\text { During } \\
\text { intervention }\end{array}$ & T2 \\
\hline $\begin{array}{l}\text { Participant } \\
\text { demographics }\end{array}$ & $\begin{array}{l}\text { Parent for child } \\
\text { and family }\end{array}$ & 2 & $N=20$ & - & - \\
\hline $\begin{array}{l}\text { Physical activity } \\
\text { (accelerometry) }\end{array}$ & Child & $1 \& 2$ & $N=70$ & $N=70$ & - \\
\hline \multirow{2}{*}{$\begin{array}{l}\text { Child vegetable } \\
\text { and fruit consumption } \\
\text { (non-consecutive } \\
\text { 3-day food records) }\end{array}$} & \multirow[t]{2}{*}{ Parent for child } & 1 & $N=23$ & - & $N=10$ \\
\hline & & 2 & $N=15$ & & $N=10$ \\
\hline \multirow{2}{*}{$\begin{array}{l}\text { Recognition of hunger } \\
\text { and fullness cues }\end{array}$} & \multirow[t]{2}{*}{ Child } & 1 & $N=25$ & - & $N=25$ \\
\hline & & 2 & $N=29$ & & $N=28$ \\
\hline $\begin{array}{l}\text { Physical activity } \\
\text { parenting practices }\end{array}$ & Parent & 1 & $N=16$ & - & $N=11$ \\
\hline \multirow[t]{2}{*}{ Home food availability } & \multirow[t]{2}{*}{ Parent } & 1 & $N=16$ & - & $N=10$ \\
\hline & & 2 & $N=21$ & & $N=13$ \\
\hline Parent satisfaction & Parent & 2 & - & - & $N=13$ \\
\hline
\end{tabular}

Pilot Study 1 = SAGE 1 and Pilot Study 2 = SAGE 2 field trips and teacher in-service days. Two ECEC were invited in Phoenix and agreed to participate. After sites were identified, parents were asked to participate in a parents' night event which was used for promotional and recruitment purposes. At parents' night, parents of children between the ages of 3 and 5 years were provided with a consent document that explained their and their child's participation in the study. A research assistant was present to explain the informed consent form and answer any questions. Parents who were unable to attend parent's night were informed of the study by research assistants as they dropped off or picked up their child. Once the parents understood the informed consent and their role in the study, they had the opportunity to enroll their child in the intervention.

\section{Intervention overview}

The SAGE curriculum was implemented in participating centers twice a week in 1 hour sessions. Children participated in 12 one-hour sessions that included songs, games, and interactive learning activities involving garden maintenance and taste tests. Research assistants (i.e. undergraduate and graduate students) were paired and trained to deliver the intervention and were taught classroom management skills. All research assistants attended weekly meetings with the project director and principal investigator in order to give a report on program delivery and to discuss any challenges and potential barriers. Weekly newsletters developed in consort with our $C A B$ were sent home with the children and used to engage parents in the program. Newsletters were available in English and Spanish and included information about what was going on in the classroom that week, to keep parents engaged and knowledgeable about SAGE. Newsletters also offered easy ideas for culturally tailored home activities and recipes, along with highlighting community resources that promoted PA and F\&V consumption such as farmer's markets or local gardening activities. Figure 1 presents a sample newsletter.

\section{Measures}

Reach of the population was measured as the sample representativeness of the population of the Census tract in which the ECEC were located. Using a written survey, parents from SAGE 2 reported on child age, gender, ethnicity and language spoken at home as well as family income (See Table 2). The decision to employ the demographic survey was made following SAGE 1; therefore, demographic data from parents whose children participated in SAGE 1 were unavailable. From the American Community Survey, 2009-2013 5-year estimates were used to indicate neighborhood sociodemographic variables at the Census tract level for each ECEC and to determine how representative the 


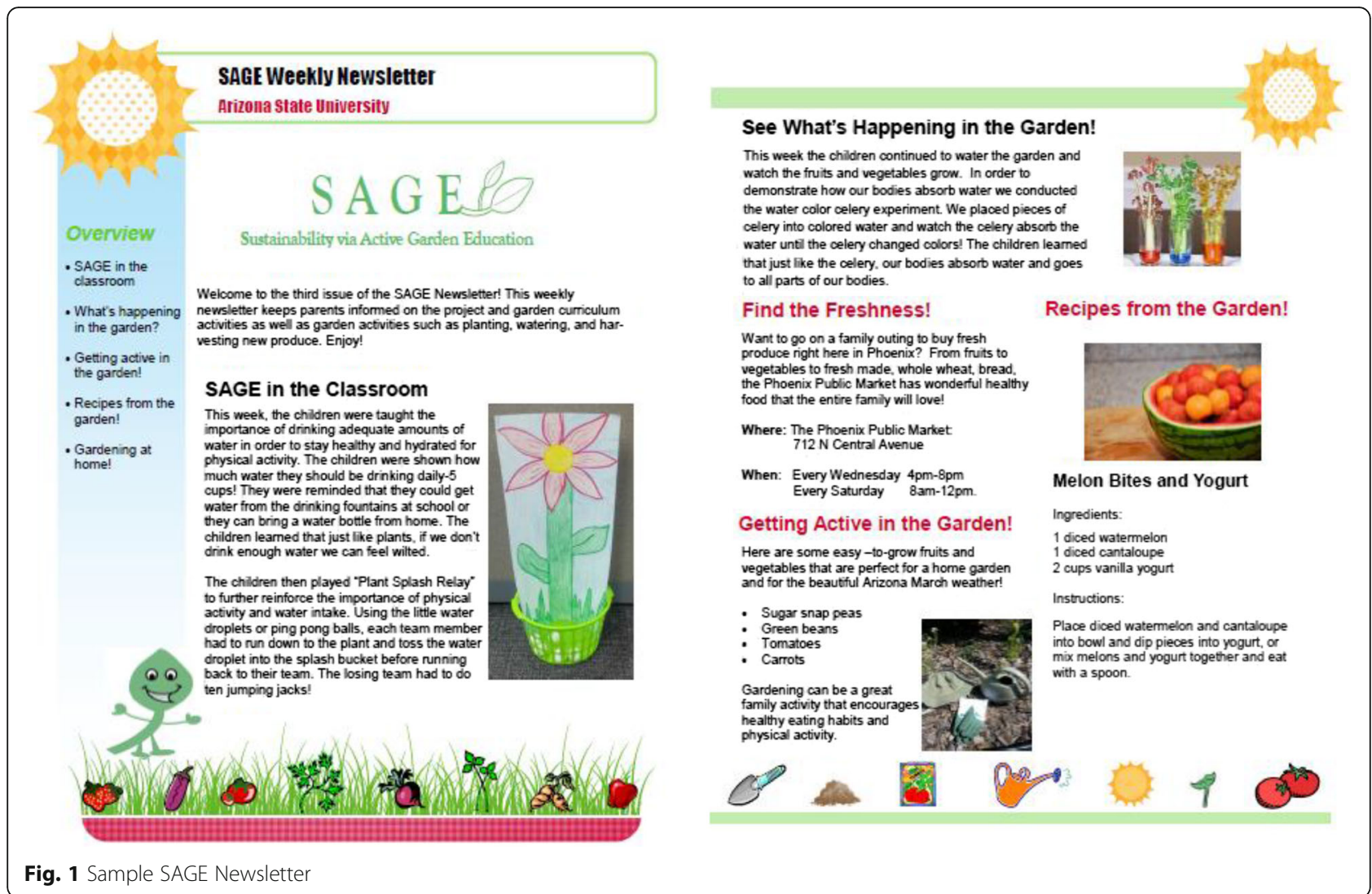

participants whom we enrolled were of the surrounding area [47].

Efficacy was measured at the child (PA, F\&V, and eating in the absence of hunger), parent (parenting practices and knowledge) and home environment (F\&V availability) levels.

Child physical activity, including light, moderate, and vigorous PA, was measured using ActiGraph GT3X accelerometers. Accelerometers were worn around the waist, centered over the right hip. During the intervention, children wore the accelerometer for 1 hour twice a week during the SAGE sessions only. SAGE staff fitted participating children with their designated devices upon arriving at ECEC for lessons, monitored device positioning throughout lessons, assisted children with realigning them as necessary, and collected devices after each lesson for data downloading and processing. Devices were initialized to collect activity at $60 \mathrm{~Hz}$, and light, moderate, and vigorous PA were processed in 15-second epochs according to validated cut-points for preschool aged children [48]. Specifically, light activity was defined as $800-1679$ counts per minute (CPM), moderate activity as 1680-3367 CPM, and vigorous activity as at least 3368 CPM [48]. Accelerometers were initialized to start recording activity $10 \mathrm{~min}$ before and to continue recording activity $10 \mathrm{~min}$ after lessons (80 $\mathrm{min}$ total) to account for slight variations in lesson start and stop times. For each lesson, SAGE staff recorded the exact time at which lessons started, and, for purposes of accelerometer data processing, SAGE lessons were assumed to end $60 \mathrm{~min}$ after this time. Therefore, only $60 \mathrm{~min}$ of accelerometermeasured PA were possible for each SAGE lesson. Minutes of PA in each of the three intensities were combined, so that PA during SAGE lessons could be compared to the IOM recommendation of $15 \mathrm{~min}$ of total PA per hour, and sedentary (non-PA) time was calculated as the result of 60 min minus the total of light, moderate, and vigorous PA minutes. The same procedure was repeated for each of the SAGE lessons (12 in Houston, ten in Phoenix), and average minutes of activity and sedentary time per lesson attended were calculated for each child at each intervention site. Children also wore accelerometers in their ECEC for one hour the week prior to the SAGE program, during the same time at which SAGE lessons were scheduled. For example, if SAGE were due to be delivered on Tuesday at 9 am, then the pre-test would be done during the Tuesday at 9 am during the week preceding the intervention commencement. These data, processed in the same manner described above, were used to compare PA during SAGE lessons to the PA children may perform during a similar, non-SAGE hour in their ECEC. 
Table 2 Participant characteristics of those in SAGE Pilot 2, $N=20$

\begin{tabular}{|c|c|}
\hline Characteristic & $N(\%)$ \\
\hline \multicolumn{2}{|l|}{ Ethnicity } \\
\hline White & $1(5 \%)$ \\
\hline African American & $2(10 \%)$ \\
\hline Hispanic or Latino & $13(65 \%)$ \\
\hline Asian & $2(10 \%)$ \\
\hline Native American & $1(5 \%)$ \\
\hline Other & $1(5 \%)$ \\
\hline \multicolumn{2}{|l|}{ Country of Origin } \\
\hline United States & $13(65 \%)$ \\
\hline Mexico & $4(20 \%)$ \\
\hline United Kingdom & $2(10 \%)$ \\
\hline \multicolumn{2}{|l|}{ Language } \\
\hline English & $11(65 \%)$ \\
\hline Spanish & $7(35 \%)$ \\
\hline More than one language & $2(10 \%)$ \\
\hline \multicolumn{2}{|l|}{ Education $^{a}$} \\
\hline Less than high school & $4(20 \%)$ \\
\hline High school or GED & $8(40 \%)$ \\
\hline College or higher & $4(20 \%)$ \\
\hline \multicolumn{2}{|l|}{ Income } \\
\hline Less than $\$ 10,000$ & $2(10 \%)$ \\
\hline$\$ 15,000-\$ 19,000$ & $3(15 \%)$ \\
\hline$\$ 20,000-\$ 24,999$ & $1(5 \%)$ \\
\hline$\$ 25,000-\$ 29,999$ & $2(10 \%)$ \\
\hline$\$ 30,000-\$ 39,999$ & $2(10 \%)$ \\
\hline$\$ 40,000-\$ 49,999$ & $1(5 \%)$ \\
\hline$\$ 50,000-\$ 59,999$ & $2(10 \%)$ \\
\hline$\$ 60,000$ or more & $1(5 \%)$ \\
\hline Not Reported & $6(30 \%)$ \\
\hline
\end{tabular}

${ }^{a}$ Note. Column does not total to $100 \%$ because of missing data for four participants

Child vegetable and fruit consumption was measured with non-consecutive 3-day food records from parents, which are validated and preferred methods of dietary assessment among preschoolers [49-51]. Parents were trained to complete the food records, taught portion sizes using food models, and provided with phone support. The United States Department of Agriculture's super tracker software was used to assess food records [52]. Research assistants inputted the data from the food records onto the software. Super tracker then generated nutrient intake reports which provided the total cups of fruits and vegetables consumed on each day that data was available. Totals were averaged across the 3 days to provide the average number of cups of fruit and vegetables consumed per day.
Child recognition of hunger and fullness cues was measured by adapting the laboratory Eating in the Absence of Hunger test [53] to the classroom setting to determine the degree to which children ate in the absence of physiologic hunger [2, 54]. In the adapted protocol, trained research assistants conducted the assessment following a center provided meal. Tests were done during regular SAGE sessions which varied by ECEC. At the beginning of the assessment, pretend play was used to teach concepts of hunger and fullness using three tummy dolls, one doll with a full tummy, one doll with a tummy that was just right, and one doll with an empty tummy. Children were asked to identify their level of satiety using the tummy dolls to reinforce that the full tummy doll had eaten too much, the empty tummy doll had not eaten enough, and the just right tummy doll had eaten just enough to feel energetic for play time. Children were then given two palatable, center approved snacks in pre-weighed snack bags. In SAGE 1, one snack bag contained a salty snack of pretzels $(20 \mathrm{~g}$, $71 \mathrm{kcals}$ ) and the other snack bag contained a sweet snack of unwrapped M\&Ms (28 g, $136 \mathrm{kcals})$. In SAGE 2, one snack bag contained Cheezit crackers (30 g, $136.8 \mathrm{kcals})$ and the other snack bag contained animal crackers (30 g, 150 kcals).

The children were instructed to taste one piece of each snack and were asked to rate their preference for the snack using a yummy, yucky, or just okay face to ensure that each snack was considered acceptable by the children. The children were then told that they could play with the toys in the classroom or continue snacking. After $10 \mathrm{~min}$, instructors collected the snack bags and brought them back to the lab for weighing.

The Preschooler PA Parenting Practices survey is a 17 item instrument that measures the degree to which parents encourage their child to be physically active. Responses from all items are summed with a higher score indicating parenting practices that are more supportive of physical activity. This instrument has been validated for use among parents of preschoolers, including Latino parents, and has shown moderate to excellent test-retest reliability $(0.56-0.85)$ [55].

The FEV Home Availability questionnaire was used to measure F\&V items in the home. This self-report questionnaire has strong internal consistency $\alpha=0.79$ among parents of preschoolers and validity with home-inventory checks with parents of 4th and 6th graders [56].

Adoption was measured by calculating the percentage of ECEC that participated in SAGE from the total ECEC that were invited to participate.

Implementation was defined as the number of sessions implemented and the number of activities completed per session (songs, games, hunger/fullness activity, taste 
testing, science experiments, and garden activity). Activities were coded as completed or not completed by research assistants delivering lessons on a formatted fidelity checklist after a sample of $63 \%$ of lessons completed in SAGE Pilot 1 and 90\% of lessons completed in SAGE Pilot 2. Checklists were not completed in all sessions owing to staffing and resource limitations.

Potential for maintenance was measured by a parent satisfaction survey. Parents completed a survey of 9 items measuring their level of satisfaction with their participation in the SAGE program and their interaction with the research team. The survey also asked parents about physical activity and nutrition knowledge gained through SAGE and the extent to which children engaged in SAGE activities in the home. Responses were recorded using a 5 point Likert scale where $1=$ not satisfied and $5=$ completed satisfied. See Table 3 .

\section{Analyses}

Descriptive analyses (e.g., percentages) were used to evaluate exploratory outcomes related to reach, adoption, implementation, and potential for maintenance. Repeated measures ANOVA and ANCOVA (controlling for the ECEC each child attended as a potential covariate) were used to evaluate outcomes related to efficacy, including changes in PA from pre-intervention lessons to SAGE lessons and changes in F\&V intake and eating in the absence of hunger from pre- to post-intervention. Repeated measures ANOVA and ANCOVA were also used to examine changes in home availability of fruits and vegetables and parenting physical activity practices. Differences between outcome measures were screened

Table 3 Percent of parents that were satisfied with the SAGE program and reported an increase in health knowledge ( $N=13)$

Item $n(\%)$

Parents satisfied with their child's participation

12(92)

in the SAGE program.

Parents satisfied with the level of communication from the project team.

$8(62)$

Parents satisfied with the helpfulness of the SAGE project team.

Parents that indicated SAGE improved their child's knowledge of nutrition.

Parents that indicated SAGE improved their child's knowledge of physical activity.

Parents that indicated SAGE improved their own knowledge of nutrition.

Parents that indicated SAGE improved their own knowledge of physical activity.

Parents that indicated their child shared information learned in the SAGE program at home.

Parents that indicated their child asked to do activities learned in the SAGE program, like sing songs or play games, at home. to insure they fit roughly normal distributions. All analyses were conducted using IBM SPSS version 22 [57], and differences were considered significant at $p<.05$.

\section{Results \\ Reach}

The ECEC in SAGE Pilot 2 were located in two separate Census tracts in Phoenix $(n=2)$ with residents from a wide range of sociodemographic backgrounds. Based on reports from parents from SAGE 2 (see Table 2; $N=20$ ) children (male $=55 \%$, female $=45 \%$ ) were, on average, $3.9(S D=.72)$ years old. The majority of parents identified as Hispanic or Latino (65\%) and reported that their country of origin was the U.S. (65\%). The language most predominantly spoken in the home was English (55\%) with 35\% reporting that Spanish was predominantly spoken in the home. Income was evenly distributed and most parents had a high school $(40 \%)$ or college $(20 \%)$ education. The sample favorably represented the residents of Census tracts containing ECEC, which were $52 \%$ Hispanic or Latino ( $S D=15.5 \%$ ), had $64 \%$ of adults 25 or older had completed high school or its equivalent $(S D=7.8 \%)$, and $44 \%$ of adults 25 or older had completed at least some college $(S D=9.2 \%)$. Median household income of Census tracts containing ECEC was, on average, $\$ 19,430(S D=\$ 3,665)$ [47]. In SAGE 1, children attended $63 \%$ of the sessions, on average $(\mathrm{SD}=26$, range $=8-100)$. In SAGE 2, children attended $78 \%$ of the sessions, on average $(\mathrm{SD}=15$, range $=50-100)$.

\section{Efficacy \\ Physical activity}

Table 4 compares PA and sedentary time during a preintervention hour to PA and sedentary time during SAGE lessons for SAGE 1 and SAGE 2. Before controlling for ECEC as a potential covariate, increases in PA and decreases in sedentary time were statistically significant in both SAGE 1 and SAGE 2. In SAGE 1, mean PA increased from $8.70 \mathrm{~min}(S D=5.97)$ in a preintervention hour to $14.10 \mathrm{~min}(S D=4.95)$ during SAGE lessons $[F(28)=23.70, p<.05]$, and mean sedentary time decreased from $51.30 \mathrm{~min}(S D=5.97)$ in a preintervention hour to $45.90 \mathrm{~min}(S D=4.95)$ during SAGE lessons $[F(28)=23.70, p<.001]$. In SAGE 2 , mean PA increased from $8.62 \min (S D=3.99)$ in a pre-intervention hour to $13.31 \mathrm{~min}(S D=4.35)$ during SAGE lessons $[F(40)=39.56, p<.001]$, and mean sedentary time decreased from $51.38 \mathrm{~min}(S D=3.99)$ in a pre-intervention hour to $46.69 \mathrm{~min}(S D=4.35)$ during SAGE lessons $[F(40)=39.56, p<.001]$. Controlling for ECEC as a potential covariate, the change in PA observed in SAGE 1 was no longer statistically significant $[F(27)=1.65, p=.21]$, and there was no significant interaction between change in PA and ECEC $[F(27)=.13, p=.72]$. The change in 
Table 4 Comparison of accelerometer-measured physical activity between a pre-intervention hour and SAGE lessons

\begin{tabular}{|c|c|c|c|c|c|c|c|c|c|c|}
\hline & \multicolumn{5}{|l|}{ SAGE $1(N=29)$} & \multicolumn{5}{|c|}{ SAGE $2(N=41)$} \\
\hline & $\begin{array}{l}\text { Pre-intervention } \\
{[\text { mean(SD)] }}\end{array}$ & $\begin{array}{l}\text { SAGE lessons } \\
(n=12) \\
{[\text { mean(SD)] }}\end{array}$ & $d f$ & $F$ & $p$ & $\begin{array}{l}\text { Pre- } \\
\text { intervention } \\
\text { [mean(SD)] }\end{array}$ & $\begin{array}{l}\text { SAGE lessons }(n=10) \\
\text { [mean(SD)] }\end{array}$ & $d f$ & $F$ & $p$ \\
\hline \multirow[t]{2}{*}{$\begin{array}{l}\text { Physical activity } \\
\text { (min) }\end{array}$} & $\begin{array}{l}8.70 \\
(5.97)\end{array}$ & $\begin{array}{l}14.10 \\
(4.95)\end{array}$ & 28 & 23.70 & $<.05$ & $\begin{array}{l}8.62 \\
(3.99)\end{array}$ & $\begin{array}{l}13.31 \\
(4.35)\end{array}$ & 40 & 39.56 & $<.001$ \\
\hline & \multicolumn{2}{|l|}{ Controlling for ECEC } & 27 & 1.65 & .21 & \multicolumn{2}{|c|}{ Controlling for ECEC } & 39 & 4.11 & .05 \\
\hline \multirow[t]{2}{*}{$\begin{array}{l}\text { Sedentary time } \\
\text { (min) }\end{array}$} & $\begin{array}{l}51.30 \\
(5.97)\end{array}$ & $\begin{array}{l}45.90 \\
(4.95)\end{array}$ & 28 & 23.70 & $<.05$ & $\begin{array}{l}51.38 \\
(3.99)\end{array}$ & $\begin{array}{l}46.69 \\
(4.35)\end{array}$ & 40 & 39.56 & $<.001$ \\
\hline & Controling for ECEC & & 27 & 1.65 & .21 & \multicolumn{2}{|c|}{ Controlling for ECEC } & 39 & .08 & .78 \\
\hline
\end{tabular}

sedentary time observed in SAGE 1 was also no longer statistically significant after controlling for ECEC as a potential covariate $[F(27)=, 1.65 p=.21]$, and there was no significant interaction between change in sedentary time and ECEC $[F(27)=.13, p=.72]$. In SAGE 2, the change in PA from the pre-intervention hour to during lessons remained significant after controlling for ECEC as a potential covariate $[F(39)=4.11, p=.05]$, but there was no significant interaction between change in PA and ECEC $[F(39)=.08, p=.78]$. The change in sedentary time observed in SAGE 2 also remained statistically significant after controlling for ECEC $[F(39)=4.11, p=.05]$, but there was no significant interaction between change in sedentary time and ECEC $[F(39)=.08, p=.78]$.

\section{Dietary habits}

Food records showed that children ate an average of .72 $(S D=.58)$ cups of vegetables per day at baseline and an average of $.77(S D=.19)$ cups of vegetables per day after participating in SAGE; however, this increase was not significant before $(F(1,10)=.072, p>.05)$ or after controlling for center $(F(1,0)=.065, p>.05)$. Food records also showed that children ate an average of .99 $(S D=.87)$ cups of fruit per day at baseline and an average of $1.15(S D=.76)$ cups of fruit per day after participating in SAGE. Similarly, the increase in fruit consumption was not significant before $(F(1,10)=.343$, $p>.05)$ or after controlling for center $(F(1,9)=.002$, $p>.05)$. Table 5 presents information on child dietary habits, parents and home environment.

\section{Eating in the absence of hunger}

Kilocalories consumed in the absence of hunger significantly increased from pre to post-intervention. The average number of kilocalories consumed in the absence of hunger at baseline was $68.51 \quad(S D=66.07)$ and the average number of kilocalories consumed in the absence of hunger post-intervention was 94.54 $(S D=59.94)$. This increase was statistically significant before $(F(1,47)=-7.162, p=.01)$; however, the increase in kilocalories consumed was not significant after controlling for center $(F(1,46)=.002, p>.05)$.

\section{Parent physical activity practices}

The Preschooler Physical Activity Parenting Practices (PPAPP) survey was used to measure parenting practices that encouraged PA in SAGE 2 parents. The average PPAPP score at baseline was $M=57.3(S D=8.73)$ and $M$ $=62.64(S D=4.32)$ at post-intervention. The increase in parenting practices that encouraged PA was not significant before $(F(1,6)=4.603, p=.076)$ or after controlling for center $(F(1,5)=4.051, p>.05)$.

Table 5 Child eating habits and parent and home outcomes pre- and post-intervention in SAGE pilot studies

\begin{tabular}{|c|c|c|c|c|}
\hline & \multicolumn{2}{|c|}{ SAGE Pilot $1(N=29)$} & \multicolumn{2}{|c|}{ SAGE Pilot $2(N=41)$} \\
\hline & $\begin{array}{l}\text { Pre-Intervention } \\
\text { M (SD) }\end{array}$ & $\begin{array}{l}\text { Post-Intervention } \\
M(S D)\end{array}$ & $\begin{array}{l}\text { Pre-Intervention } \\
M(S D)\end{array}$ & $\begin{array}{l}\text { Post-Intervention } \\
M(S D)\end{array}$ \\
\hline \multicolumn{5}{|l|}{ Fruit and vegetable intake } \\
\hline Vegetable Intake (cups) & $.73(.60)$ & $.75(.20)$ & $.70(.63)$ & $.78(.21)$ \\
\hline Fruit Intake (cups) & $.99(.36)$ & $1.33(.81)$ & $.98(1.31)$ & $.93(.71)$ \\
\hline Eating in the Absence of Hunger (kCals) & $80.63(60.54)$ & $102.03(63.32)$ & $55.33(70.57)$ & $86.39(56.29)$ \\
\hline Parenting Physical Activity Practices & - & - & $59.0(7.02)$ & $63.0(5.32)$ \\
\hline \multicolumn{5}{|l|}{ Home availability of F\&V } \\
\hline Vegetables (servings) & $11.83(2.48)$ & $12.83(2.79)$ & $6.27(4.56)$ & $6.36(4.15)$ \\
\hline Fruits (servings) & $13.17(4.92)$ & $13.5(5.72)$ & $12.36(8.79)$ & $12.73(8.21)$ \\
\hline
\end{tabular}




\section{Home food environment}

Parents reported an average of 8.24 ( $S D=4.74)$ servings of vegetables available in the home at baseline and an average of 8.65 ( $S D=4.83$ ) servings of vegetables available in the home after participating SAGE; this increase was not significant before $(F(1,16)=.536, p>.05)$ or after controlling for center $(F(1,15)=.437, p>.05)$. Parents reported an average of $12.65(S D=7.48)$ servings of fruit available in the home at baseline and an average of 13.0 $(S D=7.25)$ servings of fruit available in the home after participating in SAGE; this increase was also not significant before $(F(1,16)=.202, p>.05)$ or after controlling for center $(F(1,15)=.464, p>.05)$.

\section{Adoption}

Four of five invited ECEC participated in Houston SAGE Pilot 1, and both of the invited ECEC participated in Phoenix SAGE Pilot 2 suggesting high rates of adoption (86\%).

\section{Implementation}

Implementation was moderate to high. Each center delivered at least ten of the 12 SAGE lessons, suggesting good implementation (83\%). Class size varied greatly as some centers were larger than others. Smaller centers averaged 3-7 children per session and larger centers averaged 10-19 children per session.

In Houston, SAGE Pilot 1, across all ECEC lessons, seven out of ten songs (70.0\%), 40 out of 49 possible games $(81.6 \%), 20$ out of 30 hunger and fullness activities (86.7\%), 29 out of 30 taste tests (96.7\%), seven out of nine science experiments (77.8\%) and 20 out of 21 garden activities (95.2\%) were completed. In Phoenix in SAGE Pilot 2 across all ECEC lessons, ten out of 11 songs (90.9\%), 46 out of 49 possible games (93.9\%), 17 out of 18 hunger and fullness activities (94.4\%), 18 out of 18 taste tests (100.0\%), three out of four science experiments $(75.0 \%)$ and 13 out of 13 garden activities (100.0\%) were completed.

\section{Potential for maintenance \\ Parent perceptions}

Reports from parent satisfaction surveys indicated that almost all (92\%) parents were satisfied with their child's participation in SAGE. The majority of parents were satisfied with the level of communication (62\%) and helpfulness (62\%) from the SAGE team. Most parents believed that participating in SAGE improved their child's knowledge of PA (77\%) and nutrition (85\%). The majority of parents also believed that participating in SAGE improved their own knowledge of PA (69\%) and nutrition (77\%). Parents reported that $31 \%$ of children shared information learned from SAGE in the home and a little over half of the children requested to do activities learned in SAGE (54\%), like sing songs or play games, at home. Parent survey responses are presented in Table 3.

\section{Discussion}

This study presents the findings from the SAGE Pilot tests and demonstrates that a PA and F\&V garden-based education program for ECEC can achieve good reach, implementation, and efficacy in increasing PA as well as demonstrating high potential for maintenance. Study recruitment was well received with high levels of participation and good representation of underserved communities, and strong implementation. PA almost doubled during SAGE lesson time compared to regular lesson time, approaching IOM recommended amounts suggesting high efficacy. In contrast, the SAGE Pilot studies were less successful at improving dietary habits. As well, although popular with parents, parenting practices and home environments did not show significant change as a result of child participation in SAGE.

SAGE showed good efficacy for increasing PA by demonstrating that garden-based education can significantly increase PA in the ECEC, the place where young children are typically at their least active throughout their entire waking day [16]. This compares favorably with one study done in schools which showed increases in PA in older children participating in a school garden program [32]. On average, SAGE's one hour lessons, offered about twice a week, approached the IOM recommendation of at least 15 min of activity during waking hours [15]. In SAGE 1, the increase in PA from preintervention lessons to lessons during the intervention was no longer significant after controlling for ECEC. This may reflect differences in the regularly-scheduled activities taking place in centers during pre-intervention lesson PA measurement, or differences in ECEC indoor or outdoor spaces that influenced PA during intervention activities. In contrast, SAGE demonstrated poor efficacy in enhancing eating behaviors in children, consistent with one other garden-based study in ECEC [58]. Although there was a small increase, it was not what had been anticipated from several previous school-based studies [27-30]. It may be that the intervention did not provide sufficient dose or duration to change eating behaviors, although the SAGE intervention was more intensive than a previous study [58]. Possibly parents may have perceived that the additional emphasis on fruit and vegetables during ECE time could compensate for emphasis in improving dietary quality at home. The current results may also result from relatively low compliance with dietary assessment records from parents that resulted in a small sample size. This was designed as a small pilot study, and future work is needed to determine how to increase compliance with assessment methods, or 
alternative assessment strategies that reduce participant burden should be used.

Children's eating in the absence of hunger actually increased post intervention which was the opposite of what we expected. As has been previously reported, we used an adapted protocol suitable for a community setting [54]. Although this pioneering work has helped to lead the science in the assessment of eating in the absence of hunger in young children, the adaptation met with barriers. The team was unable to ensure that children had eaten the meal, struggled with finding appropriate snacks (complying with school rules and accommodating food allergies) and faced teaching complex concepts of hunger and fullness, which may have impacted results. We received anecdotal feedback from our initial pilot test (SAGE Pilot 1) from our CAB, ECEC directors and parents to change the snack stimulus. Future work is needed to overcome these barriers in community settings [54].

The SAGE Pilot tests were unable to detect whether parenting practices focused on PA promotion had increased, although the direction of trend suggested that it might be happening. This interpretation is consistent with the parent survey questions that suggested that SAGE was well liked, and parents believed that children's knowledge had increased. At the same time, no changes in home availability of F\&V were detected. Both of these measures suffered from low response rates from parents. As noted above, resources for better engagement and assessment strategies are needed. Methodological limitations in SAGE Pilots 1 and 2 include the potential for recall and favorability bias from parents on surveys that were used to evaluate efficacy and potential for maintenance outcomes. Further, it will be important to collect parents' demographic data from all participating ECEC and to collect accelerometer data from children during larger samples of pre- and post-SAGE lessons.

Despite limitations in the ability to detect efficacy, there was very high adoption of the SAGE Pilots, because nearly all of the ECEC that were invited participated. High rates of implementation showed good fidelity to the curriculum. Differences in implementation variation between the two studies were due to a myriad of factors which included class size variability, time constraints, variation between the two pilot studies as well as the natural unpredictability of young children necessitating a flexible approach to curriculum delivery. Additional reports previously published suggested that SAGE was well received by ECEC staff who believed it easy and fun to implement (Soltero EG, Parker NH, Mama SK, Ledoux TA, Lee RE: Implementation and adoption of Sustainability via Active Garden Education (SAGE): Lessons learned from early care and education centers, forthcoming). ECEC staff also reported that SAGE complemented their existing curricula and filled a need for stronger health education. SAGE reached a representative population of the local neighborhoods. Those parents who did respond to parent surveys were very pleased with their child's participation in SAGE. Taken together the strong reach, adoption, and implementation suggest the potential for maintenance of SAGE. Future investigations should examine longer term efficacy and adoption of the SAGE program, including training teachers and staff to implement lessons.

The SAGE Pilot tests demonstrate that it is possible to increase PA among young children in the ECEC with active programming, and ECEC staff and parents are interested and pleased with this type of programming. Additional strengths include a rigorous development protocol, a larger sample size than previously published studies of ECEC $(N=6)$ in two US cities, a carefully crafted and theoretically grounded intervention strategy relying on a participatory approach that involved the people whom the intervention served. SAGE relied on a thorough assessment and valid and reliable measures, although it suffered from low sample size on some measures. SAGE was also low cost and innovative. Limitations included an inability to detect efficacy on nutrition and parenting related outcomes, probably a result of low sample size. Important measures necessary to establish reach were not collected or available, and better planning is needed in future studies to document reach appropriately. Although all children who were present participated in the curriculum, we were only able to document those that had parent consent. In addition to children without informed consent, it is also likely that siblings and other family members may have benefited from the SAGE curriculum. These exo-level ecological linkages are fodder for future investigations. Few parents returned survey measures that had been sent home with children. Qualitative interviews suggested much higher parent interest, in part a result of efforts made to foster parent engagement (e.g., newsletters, announcements at parent night), suggesting more work should be done to engage parents and reduce the burden of completing questionnaires [46].

\section{Conclusions}

Results suggest that SAGE is an important first step in meeting PA recommendations and improving health education in ECEC in the US. SAGE demonstrated good reach, efficacy, adoption, implementation and high potential to be sustained in the ECEC setting, and reflects careful development involving stakeholders. Future research should test the sustainability of SAGE by continuing to work with ECEC staff, providing resources for ongoing technical support and continued efforts at 
engaging parents. SAGE was designed as a transcultural intervention, useful for improving early child health across a variety of cultures and communities via a long term participatory process. As a result of this highly engaged process, SAGE provides innovative and fun, garden-based programming that translates policy guidelines into practice to achieve increases in PA in preschool aged children with high internal and external validity suggesting high translatability to other cultural contexts.

\section{Abbreviations}

ECEC: Early care and education center; F\&V: Fruits and vegetables; PA: Physical activity; SAGE: Sustainability via Active Garden Education

\section{Acknowledgements}

The authors thank members of the Community Advisory Board from the Science \& Community project and students from the Understanding Neighborhood Determinants of Obesity (UNDO) research groups at the University of Houston and Arizona State University for their work to develop and deliver the SAGE program.

\section{Funding}

This study was supported by a grant awarded to Dr. Lee from the National Institute of Child Health and Human Development of the National Institutes of Health (R21HD073685-01). The authors of this article designed the study; collected, analyzed, and interpreted data, and wrote the manuscript with only financial support from the funding body.

\section{Availability of data and materials}

The datasets from this study are available from the corresponding author on reasonable request.

\section{Authors' contributions}

All authors contributed substantially and meaningfully to this research study and the final manuscript. REL secured grant funding to support the manuscript and served as the principal investigator of the SAGE project. REL, NHP, EGS, SKM, TAL, and LM designed the methodology of the study and conceptualized the manuscript. All authors participated in the preparation of this manuscript and approved the final product.

\section{Competing interests}

The authors declare that they have no competing interests.

\section{Consent for publication}

Not applicable.

\section{Ethics approval and consent to participate}

All study activities in Houston were approved by the University of Houston Committee for the Protection of Human Subjects, and all study activities in Phoenix were approved by the Arizona State University Institutional Review Board. Written, informed consent to participate was obtained from a parent or legal guardian representing each child involved in study activities, and assent was obtained from each child.

\section{Publisher's note}

Springer Nature remains neutral with regard to jurisdictional claims in published maps and institutional affiliations.

\section{Author details}

${ }^{1}$ Center for Health Promotion and Disease Prevention, College of Nursing and Health Innovation, Arizona State University, Phoenix, AZ, USA. ${ }^{2}$ Texas Obesity Research Center, Department of Health and Human Performance, University of Houston, Houston, TX, USA. ${ }^{3}$ Department of Kinesiology, College of Health and Human Development, The Pennsylvania State University, University Park, PA, USA. ${ }^{4}$ Department of Health Disparities Research, University of Texas M.D. Anderson Cancer Center, Houston, TX, USA.
Received: 27 September 2016 Accepted: 2 March 2017

Published online: 10 March 2017

\section{References}

1. Affenito SG, Thompson DR, Franko DL, Striegel-Moore RH, Daniels SR, Barton $B A$, et al. Longitudinal assessment of micronutrient intake among AfricanAmerican and white girls: The National Heart, Lung, and Blood Institute Growth and Health Study. J Am Diet Assoc. 2007;107(7):1113-23.

2. Birch LL, Anzman SL. Learning to eat in an obesogenic environment: A developmental systems perspective on childhood obesity. Child Dev Perspect. 2010;4(2):138-43.

3. Cashdan E. A sensitive period for learning about food. Hum Nat. 1994;5(3): 279-91.

4. Cooke L. The importance of exposure for healthy eating in childhood: A review. J Hum Nutr Diet. 2007;20(4):294-301.

5. Freedman DS, Khan LK, Serdula MK, Dietz WH, Srinivasan SR, Berenson GS. Racial differences in the tracking of childhood BMI to adulthood. Obes Res. 2005;13(5):928-35.

6. Freedman DS, Khan LK, Serdula MK, Dietz WH, Srinivasan SR, Berenson GS. The relation of childhood BMI to adult adiposity: The Bogalusa Heart Study. Pediatrics. 2005;115(1):22-7.

7. Freedman DS, Wang J, Maynard LM, Thornton JC, Mei Z, Pierson RN, et al. Relation of BMI to fat and fat-free mass among children and adolescents. Int J Obes (Lond). 2005;29(1):1-8.

8. Mannino ML, Lee Y, Mitchell DC, Smiciklas-Wright H, Birch LL. The quality of girls' diets declines and tracks across middle childhood. Int J Behav Nutr Phys Act. 2004;1(1):5.

9. National Association for Sport and Physical Education. Active Start: A Statement of Physical Activity Guidelines for Children Birth to Five Years. Reston: National Association for Sport and Physical Education; 2002.

10. Resnicow K, Smith M, Baranowski T, Baranowski J, Vaughan R, Davis M. 2year tracking of children's fruit and vegetable intake. J Am Diet Assoc. 1998; 98(7):785-9.

11. Epstein LH, Paluch RA, Consalvi A, Riordan K, Scholl T. Effects of manipulating sedentary behavior on physical activity and food intake. J Pediatr. 2002;140(3):334-9.

12. Klesges $R C$, Klesges $L M$, Eck LH, Shelton ML. A longitudinal analysis of accelerated weight gain in preschool children. Pediatrics. 1995;95(1): 126-30.

13. McGuire S. U.S. Department of Agriculture and U.S. Department of Health and Human Services, Dietary Guidelines for Americans. 7th ed. Washington: U.S. Government Printing Office; 2010. January 2011. Adv Nutr. 2011; 2(3): 293-294.

14. Moore LL, Nguyen US, Rothman KJ, Cupples LA, Ellison RC. Preschool physical activity level and change in body fatness in young children. The Framingham Children's Study. Am J Epidemiol. 1995;142(9):982-8.

15. McGuire S. Institute of Medicine (IOM) Early Childhood Obesity Prevention Policies. Washington: The National Academies Press; 2011. Adv Nutr. 2012; 3(1):56-57.

16. Cerin E, Baranowski T, Barnett A, Butte N, Hughes S, Lee RE, et al. Places where preschoolers are (in)active: An observational study on Latino preschoolers and their parents using objective measures. Int I Behav Nutr Phys Act. 2016;13:29

17. Salmon J. Novel strategies to promote children's physical activities and reduce sedentary behavior. J Phys Act Health. 2010;7 Suppl 3:S299-306.

18. Graham H, Zidenberg-Cherr $\mathrm{S}$. California teachers perceive school gardens as an effective nutritional tool to promote healthful eating habits. J Am Diet Assoc. 2005;105(11):1797-800.

19. McCormack LA, Laska MN, Larson NI, Story M. Review of the nutritional implications of farmers' markets and community gardens: A call for evaluation and research efforts. J Am Diet Assoc. 2010;110(3):399-408.

20. Ozer EJ. The effects of school gardens on students and schools: Conceptualization and considerations for maximizing healthy development. Health Educ Behav. 2007;34(6):846-63.

21. Robinson-O'Brien R, Story M, Heim S. Impact of garden-based youth nutrition intervention programs: A review. J Am Diet Assoc. 2009;109(2): 273-80

22. Ohly H, Gentry S, Wigglesworth R, Bethel A, Lovell R, Garside R. A systematic review of the health and well-being impacts of school gardening: synthesis of quantitative and qualitative evidence. BMC Public Health. 2016;16:286. 
23. Ahmed AT, Oshiro CE, Loharuka S, Novotny R. Perceptions of middle school educators in Hawai'i about school-based gardening and child health. Hawail Med J. 2011;70(7 Suppl 1):11-5.

24. Lee RE, Soltero EG, Mama SK, Saavedra F, Ledoux TA, McNeill L. Developing a transcultural academic-community partnership to arrest obesity. Int Q Community Health Educ. 2013;34(3):215-33.

25. Chaufan C, Yeh J, Sigal B. Advancing family health through the Garden of Eatin:: On-site food gardens in early childhood education. Am J Public Health. 2015;105(4):625-8.

26. Gibbs L, Staiger PK, Johnson B, Block K, Macfarlane S, Gold L, et al. Expanding children's food experiences: the impact of a school-based kitchen garden program. J Nutr Educ Behav. 2013;45(2):137-46.

27. Jaenke RL, Collins CE, Morgan PJ, Lubans DR, Saunders KL, Warren JM. The impact of a school garden and cooking program on boys' and girls' fruit and vegetable preferences, taste rating, and intake. Health Educ Behav. 2012;39(2):131-41.

28. McAleese JD, Rankin LL. Garden-based nutrition education affects fruit and vegetable consumption in sixth-grade adolescents. J Am Diet Assoc. 2007; 107(4):662-5.

29. Morgan PJ, Warren JM, Lubans DR, Saunders KL, Quick GI, Collins CE. The impact of nutrition education with and without a school garden on knowledge, vegetable intake and preferences and quality of school life among primary-school students. Public Health Nutr. 2010;13(11):1931-40.

30. Parmer SM, Salisbury-Glennon J, Shannon D, Struempler B. School gardens: an experiential learning approach for a nutrition education program to increase fruit and vegetable knowledge, preference, and consumption among second-grade students. J Nutr Educ Behav. 2009;41(3):212-7.

31. Christian MS, El Evans C, Conner M, Ransley JK, Cade JE. Study protocol: can a school gardening intervention improve children's diets? BMC Public Health. 2012;12:304.

32. Wells NM, Myers BM, Henderson Jr CR. School gardens and physical activity: a randomized controlled trial of low-income elementary schools. Prev Med. 2014;69 Suppl 1:S27-33.

33. Virginia Tech College of Agriculture and Life Sciences. Reach Effectiveness Adoption Implementation Maintenance (RE-AIM). http://re-aim.org/. Accessed 6 Mar 2017.

34. Glasgow RE, Vogt TM, Boles SM. Evaluating the public health impact of health promotion interventions: The RE-AIM framework. Am J Public Health. 1999;89(9):1322-7.

35. Alhassan S, Sirard JR, Robinson TN. The effects of increasing outdoor play time on physical activity in Latino preschool children. Int J Pediatr Obes. 2007;2(3):153-8.

36. Fitzgibbon ML, Stolley MR, Schiffer L, Van Horn L, Kaufer Christoffel K, Dyer A. Two-year follow-up results for Hip-Hop to Health Jr.: A randomized controlled trial for overweight prevention in preschool minority children. J Pediatr. 2005;146(5):618-25.

37. Fitzgibbon ML, Stolley MR, Schiffer L, Van Horn L, KauferChristoffel K, Dyer A. Hip-Hop to Health Jr. for Latino preschool children. Obesity (Silver Spring). 2006;14(9):1616-25.

38. Williams CL, Bollella MC, Strobino BA, Spark A, Nicklas TA, Tolosi LB, et al. "Healthy-start": Outcome of an intervention to promote a heart healthy diet in preschool children. J Am Coll Nutr. 2002;21(1):62-71.

39. Williams $\mathrm{CL}$, Strobino BA, Bollella M, Brotanek J. Cardiovascular risk reduction in preschool children: The "Healthy Start" project. J Am Coll Nutr. 2004;23(2): 117-23.

40. National Association for the Education of Young Children. NAEYC Early Childhood Program Standards and Accreditation Criteria \& Guidance for Assessment. 2016

41. Lee RE, Cubbin C. Striding toward social justice: The ecologic milieu of physical activity. Exerc Sport Sci Rev. 2009;37(1):10-7.

42. Spence JC, Lee RE. Toward a comprehensive model of physical activity. Psychol Sport Exerc. 2003;4(1):7-24.

43. Baranowski T, Davis M, Resnicow K, Baranowski J, Doyle C, Lin LS, et al. Gimme 5 fruit, juice, and vegetables for fun and health: Outcome evaluation. Health Educ Behav. 2000;27(1):96-111.

44. Heim S, Stang J, Ireland M. A garden pilot project enhances fruit and vegetable consumption among children. J Am Diet Assoc. 2009;109(7):1220-6.

45. Lee RE, Soltero EG, Ledoux TA, Sahnoune I, Saavadra F, Mama SK, et al. Sustainability via Active Garden Education (SAGE): Translating policy to practice to meet physical activity and nutrition guidelines in early care and education. 2016. In press.
46. Lee RE, Mama SK, Soltero EG, Parker NH, Ledoux T, McNeill L, et al. Sustainability via active garden education: A CBPR project to increase PA and F\&Vs in preschoolers [abstract]. Ann Behav Med. 2015;49 Suppl 1:S134-5.

47. US Census Bureau. Selected population and housing charactersitics, 20092013 American Community Survey 5-year estimates. http://factfinder.census. gov/faces/nav/jsf/pages/searchresults.xhtml?refresh=t. (2013). Accessed 6 Mar 2017.

48. Pate RR, Almeida MJ, Mclver KL, Pfeiffer KA, Dowda M. Validation and calibration of an accelerometer in preschool children. Obesity (Silver Spring). 2006;14(11):2000-6.

49. Burrows TL, Martin RJ, Collins CE. A systematic review of the validity of dietary assessment methods in children when compared with the method of doubly labeled water. J Am Diet Assoc. 2010;110(10):1501-10.

50. Cullen KW, Watson K, Himes JH, Baranowski T, Rochon J, Waclawiw M, et al. Evaluation of quality control procedures for 24-h dietary recalls: Results from the Girls Health Enrichment Multisite Studies. Prev Med. 2004;38(Suppl):S14-23.

51. Serdula MK, Alexander MP, Scanlon KS, Bowman BA. What are preschool children eating? A review of dietary assessment. Annu Rev Nutr. 2001;21: 475-98.

52. Feskanich D, Sielaff BH, Chong K, Buzzard IM. Computerized collection and analysis of dietary intake information. Comput Methods Programs Biomed. 1989:30(1):47-57.

53. Fisher JO, Birch LL. Restricting access to palatable foods affects children's behavioral response, food selection, and intake. Am J Clin Nutr. 1999;69(6): 1264-72.

54. Soltero EG, Ledoux T, Lee RE. Feasibility and acceptability of adapting the eating in the absence of hunger assessment for preschoolers in the classroom setting. Eat Behav. 2015;19:68-71.

55. O'Connor TM, Cerin E, Hughes SO, Robles J, Thompson DI, Mendoza JA, et al. Psychometrics of the preschooler physical activity parenting practices instrument among a Latino sample. Int J Behav Nutr Phys Act. 2014;11:3.

56. Marsh T, Cullen KW, Baranowski T. Validation of a fruit, juice, and vegetable availability questionnaire. J Nutr Educ Behav. 2003;35(2):93-7.

57. Corp IBM. SPSS Statistics for Windows, Version 22.0. Armonk: IBM Corp; 2012

58. Namenek Brouwer RJ, Benjamin Neelon SE. Watch me grow: a gardenbased pilot intervention to increase vegetable and fruit intake in preschoolers. BMC Public Health. 2013;13:363.

\section{Submit your next manuscript to BioMed Central and we will help you at every step:}

- We accept pre-submission inquiries

- Our selector tool helps you to find the most relevant journal

- We provide round the clock customer support

- Convenient online submission

- Thorough peer review

- Inclusion in PubMed and all major indexing services

- Maximum visibility for your research

Submit your manuscript at www.biomedcentral.com/submit 